\title{
AGENT-BASED FRAMEWORK FOR MODELLING OF ORGANIZATION AND PERSONAL KNOWLEDGE FROM KNOWLEDGE MANAGEMENT PERSPECTIVE
}

\section{Janis Grundspenkis}

Riga Technical University, Faculty of Computer Science and Information Technology, Department of Systems Theory and Design, I Kalku Street, LV 1658, Riga, Latvia, E-mail: Janis.Grundspenkis@cs.rtu.lv

\begin{abstract}
The paper tries to bridge gap between knowledge management and artificial intelligence approaches proposing agent-based framework for modelling organization and personal knowledge. The perspective of knowledge management is chosen to develop two conceptual models - one interprets organization as an intelligent agent, another models an agent-based environment of the knowledge worker for personal and organizational knowledge management support.
\end{abstract}

Key words: knowledge worker; organization's knowledge management system; personal knowledge management; intelligent agents; multi-agent system.

\section{INTRODUCTION}

Nowadays in the information age the organizational networks has become highly variable while their environments increasingly dynamic. As a consequence, organizations should react adequately, transform their infrastructure, interpret non-standardized information for problem solving and decision making, as well as change their management strategies in order to be competitive in the rapidly changing environment. Usually there are a lot of information and knowledge within organizations, but at the same time many organizations, in particular, service organizations are "information rich and knowledge poor". The information and knowledge assets, often called

Please use the following format when citing this chapter:

Grundspenkis, Janis, 2006, in International Federation for Information Processing (IFIP), Volume 207, Knowledge Enterprise: Intelligent Strategies In Product Design, Manufacturing, and Management, eds. K. Wang, Kovacs G., Wozny M., Fang M., (Boston: Springer), pp. 62-70. 
an intellectual capital (knowledge that can be converted into value) make a great potential for organizations if utilized well (Apshvalka and Grundspenkis, 2003).

Knowledge management (KM) has become a new way of capturing and efficiently managing an organization's intellectual capital or, in other words, full past experience, skills and knowledge that is relevant for more effective performance in future. The main goal of knowledge management systems (KMS) is to provide knowledge creation (development, acquisition, inference, generation), storage (representation, preservation), aggregation (creation of meta-knowledge), use/reuse (access, analysis, application), and transfer (distribution, sharing), i.e., to support an effective knowledge flow.

KM tools and techniques afford an effective technological solution for acquisition, preservation and use of organization's knowledge. Typically it practices converting information to knowledge and connecting people. In principle, KM tools may be supported by information technology (IT) infrastructure and/or artificial intelligence (AI) techniques. Information management tools, for instance, data warehouses, data search engines, data modeling and visualization tools, etc., allow to generate, store, access, and analyze data. KM tools, such as, knowledge flow enablers, knowledge navigation systems, corporate memories, knowledge repositories and libraries, etc., in their turn, allow to develop, combine, distribute and secure knowledge. It is obvious, that a great part of functionality of both types of tools may be effectively supported by AI techniques. At the same time, it is needed to stress that the role of $\mathrm{Al}$ is underestimated and frequently even ignored by KM professionals. Analysis of a great number of publications shows that there is a difference of opinions even on fundamental terms, such as, "knowledge", "knowledge representation", "knowledge processing", etc. (Grundspenkis, 2001).

In this paper we try to bridge gaps between KM and AI. First, we suggest to interpret an organization in terms of intelligent agents. Second, we consider how intelligent agent paradigm may be integrated with the KMS, and develop a conceptual model of organization as multi-agent and knowledge management system. Finally, we describe a model of an agentbased environment of the knowledge worker that is considered to be a structure that can support the sharing and reuse of individual knowledge worker's knowledge (framework for personal KM), as well as to support an enterprise-wide knowledge, experience and lessons learnt.

The final goal of the research, presented in this paper, is to develop a model of an agent-based intelligent KMS and to implement this model into a working prototype. 


\section{ORGANIZATIONS AS INTELLIGENT AGENTS}

From the systems theory point of view, any type of organization may be considered as a set of various objects together with relationships between them. In other words, organizations are systems which components are active or passive objects (Grundspenkis and Kirikova, 2005). Agents, in turn, may be natural, e.g., humans, or artificial ones, such as, software agents and robots. Artificial agents are acting within a real environment (robots) or within a virtual environment, that is, cyberspace (robots and software agents). All agents are called knowledge workers whose decisions effect their environment, which could consist of other agents and/or passive objects, for instance, other types of software and/or hardware that include also control devices. Environment entities can be local to the agent (the same platform or machine on which agent resides) or remote, if agent is connected via some type of network with other objects (Knapik and Johnson, 1998).

A wide variety of organizations considered as collections of active objects, i.e., agents or knowledge workers, and passive objects, allow to predict that it will be impossible to develop an effective general purpose KMS usable for all classes of organizations. At the same time, the role of $\mathrm{KM}$ is steadily growing, particularly for organizations operating in rapidly changing environments. Thus, new solutions appear, new technologies are introduced, and new methodologies are developed. In (Grundspenkis and Kirikova, 2005) organization's knowledge life cycle is represented as an organization's knowledge space that is organized form of data, information and knowledge captured in past, and used at present and in the future to get additional value out of them.

Each intelligent organization is trying to reach this goal autonomously making rational decisions and taking the best possible actions. So, the interpretation of an intelligent organization as a whole using the concept of an intelligent agent is quite obvious. For details of intelligent agents, their programs and architecture see (Russell and Norvig, 2003). Intelligent organization like an intelligent agent perceives the current state of the environment, using its detectors (sensors) for data, information and knowledge acquisition. The knowledge about the current state and the goal state is used to determine actions that through effectors will be applied in the organization's environment. This output is determined on the basis of percepts and knowledge captured in the knowledge space. The interpretation of an organization in terms of intelligent agents is shown in Fig. 1. 


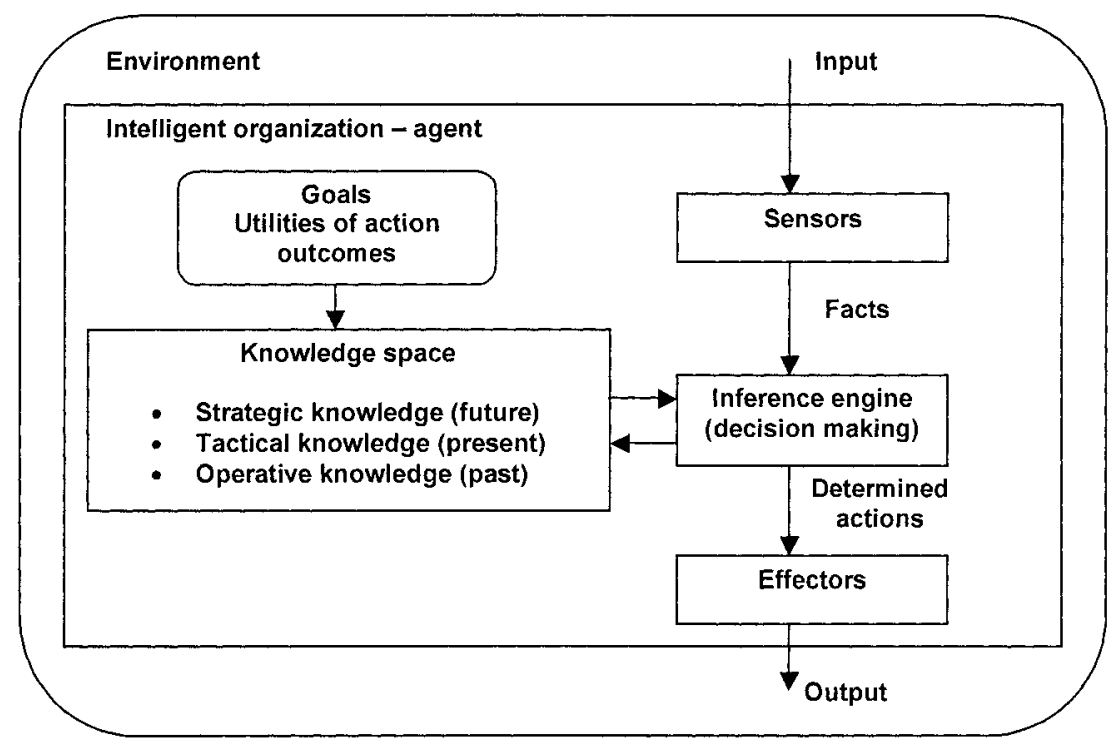

Figure 1. Organization as an intelligent agent

There are several main activities of organizations as intelligent agents that must be performed to build their intellectual capital. First, organizations must perceive and identify intellectual values, which are presented in the environment, as well as, inside the organizations themselves. Second, they must evaluate whether the identified intellectual values are sufficient for reaching the predefined goals, realizing business processes and rising the competitiveness. Third, the organizations must create an additional value from their intellectual capital by choosing more rational actions. The maintenance of the knowledge flow provided by the KMS is the vehicle for generation of new additional value from the organization's intellectual capital.

From intelligent organization - agent point of view KM means knowledge acquisition, processing, and use for rational decision making and choosing the best actions, and generation of new knowledge, i.e., systematic management of the intellectual capital of an organization. The main functions of the KMS from the agent viewpoint are the same that characterize intelligent agents in general:

- Detection of information and knowledge (the function of sensors)

- Storage of detected information and knowledge (the function of knowledge space that plays the role of memory)

- Decision making (the function of inference engine) 
- Retrieval and visualization of knowledge

All organization's business processes are supported by intelligent organization - agent activities, such as decision making and acting. Intelligent organizations - agents generate alternatives and model possible solutions, which are the results of applying the chosen actions. Finally, they make decisions knowing goals and utilities of the predicted outcomes of actions.

\section{ORGANIZATION AND PERSONAL KNOWLEDGE MANAGEMENT SUPPORTED BY MULTI-AGENT SYSTEM}

More detailed examination of business process support from the inside reveals that managers, researchers and assistants, advisers, secretaries, etc. are employed as searchers, schedulers, and planners to do the diverse mundane tasks. Let consider perspectives of intelligent support of these activities by communities of intelligent agents, or so called multi-agent systems (Knapik and Johnson, 1998; Woodridge, 2002). This "inside look" on intelligent organization - agent is shown in Fig. 2.



Figure 2. Organization's knowledge management supported by multi-agent system

The conceptual model of an intelligent organization's knowledge management system (OKMS) which is based on an intelligent agent 
paradigm and is under the development at the present moment is described in (Grundspenkis, 2003). The basic idea behind the conceptual model is that the OKMS should operate like the human brain and fulfill the following basic functions: knowledge acquisition through sensors, knowledge formalization, representation and storage in the knowledge space (memory), knowledge inference, sharing, and utilizing. As it is shown in Fig. 2, the conceptual model consists from two main parts: an intelligent organization as a multi-agent system for business process support and a KMS. The conceptual model has three layers called an "engine room", a structural layer, and a "cooperation platform". The "engine room" is an integrated set of technologies, hardware, and software to provide knowledge acquisition, storage, processing, retrieval, and representation. The purpose of the structural layer is to identify intellectual resources of the organization, and to organize knowledge to make it easily accessible and applicable. A "cooperation platform" is the physical and/or virtual environment where organization's intelligent agents may communicate with each other for effective knowledge sharing and distribution to achieve the business process goals. A "cooperation platform" maintains such components as video conferencing, chat rooms, electronic white boards, and other tools for cooperative work (groupware).

In (Grundspenkis, 2003) the potential already manifested by intelligent agents and multi-agent systems for KM is discussed and three groups of agents are marked. First, agents that may promote the KM and may be used as organization's common vehicle of the "engine room". Nowadays there already exist a number of agents that may be used as KM promoters, for example, network agents, database agents, connection and access agents, network software distribution agents, and intelligent Web agents (Knapik and Johnson, 1998; Web Intelligence, 2003). Second, among agents that provide communications, such agents as messaging agents, collaborative agents, cooperative agents, communication facilitators, team agents, and others may be listed (Knapik and Johnson, 1998; Ellis and Wainer, 2002). Third, so called personal agents are search, filtering, work-flow, and assistant agents (Knapik and Johnson, 1998). Their primary purpose is to support the knowledge work of each staff member of intelligent organization. Usually the term "knowledge worker" is used when the role and activities of staff members of modern intelligent organizations are discussed. The concept of the agent-based environment of the knowledge worker was proposed in (Grundspenkis, 2003). According to this concept the knowledge worker is embedded into a multi-agent system that consists of three circles of agents, namely personal agents, communication agents, and agents for access to external systems (network, databases, etc.) as it is shown in Fig. 3. 


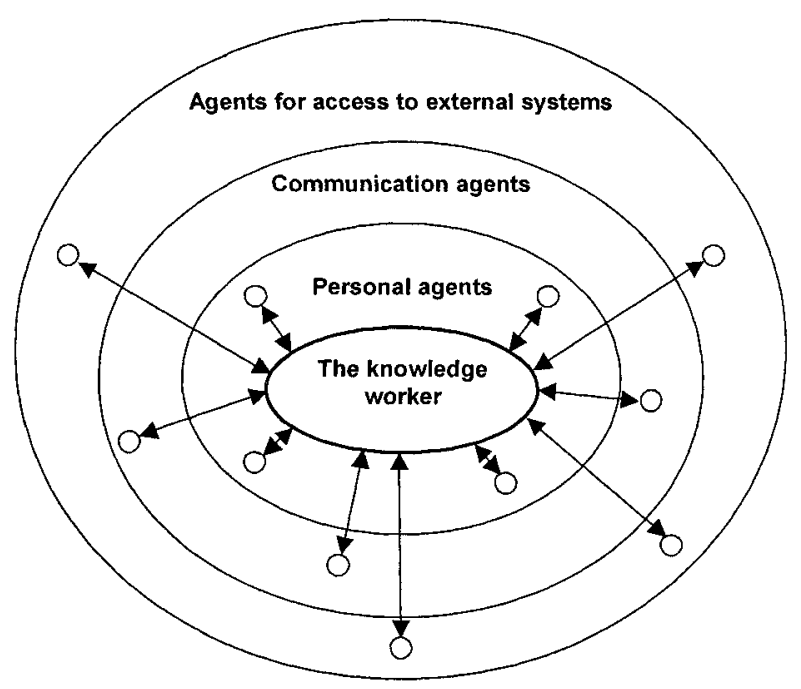

Figure 3. An agent-based environment of the knowledge worker

Knowledge management works best when knowledge workers take the initiative and responsibility for what they know, don't know, and need to know. Doing so not only makes the individual knowledge worker more valuable to the organization, but it also enhances the value of intellectual capital of an organization. The concept of personal knowledge management (PKM) emerges in this context (Apshvalka and Grundspenkis, 2005). The objectives of PKM extend further than giving employees access to intranets, systems, and standards. The final goal is to make knowledge workers better in capturing, sharing, and using knowledge, and maximizing their personal effectiveness in the social and relationship-building of their jobs (KM Magazine).

Concept of PKM is not a new concept, however, it is not notably popular in the field of KM. PKM is defined as a collection of processes that an individual needs to carry out in order to gather, classify, store, search, and retrieve knowledge in his/her daily activities (Tsui, 2002). PKM is considered from different perspectives, for instance, some authors focus on attempts how to utilize a computer to help the knowledge worker to manage his/her knowledge, others focus on problem-solving skills or arranging ideas (Apshvalka and Grundspenkis, 2005). To get a complete understanding of $\mathrm{PKM}$, it is necessary to put all perspectives together and look at this kind of $\mathrm{KM}$ as a process of managing personal information and knowledge, and arranging ideas to be able to solve problems skillfully: to see problems, set goals, generate alternatives, make decisions, perform actions, learn from 
experience, etc. So, PKM is integrated discipline that integrates many aspects, in particular, psychological, social, and technological, and many perspectives from different fields.

Nowadays technologies can help individuals to make decisions and perform actions. In complex cases more sophisticated support is needed to make knowledge worker's activities really effective. This is where such technologies as intelligent agent and multi-agent systems should help to find and generate needed information and knowledge. Due to the importance of social aspects of PKM, multi-agent systems will be perspective for information and knowledge acquisition, storage, processing, and distribution.

In PKM the concept of knowledge worker is used twofold (Apshvalka and Grundspenkis, 2005). First, the knowledge worker possesses his/her individual knowledge that need to be managed because human agents possess tacit knowledge. Second, to provide effective knowledge management, the human agent's activities should be supported by software agents for management of explicit knowledge. In this case the concept of the agent-based environment described above and shown in Fig. 3 may be used, too.

\section{CONCLUSIONS}

This paper has identified the possible role of intelligent agents and multiagent systems for organization and personal knowledge management support. Several conceptual models are discussed. First, organization as a whole is interpreted as an intelligent agent, which uses its own knowledge space for knowledge capturing. Second, some aspects how multi-agent systems may support organization and personal knowledge management are discussed.

Regardless that a lot of work should be done to achieve considerable results in implementation of the proposed framework, the potential of using intelligent agents and multi-agent systems to develop more intelligent KMS even now is rather high. We hope that conceptual model of an intelligent OKMS together with agent based environment of the knowledge worker will serve as a platform for researchers to investigate directions towards development of more and more intelligent systems for organization and personal knowledge management.

\section{REFERENCES}

1. Apshvalka, D. and Grundspenkis, J., (2003), Making organizations to act 
more intelligently in the framework of the organizational knowledge management system, in: Scientific Proceedings of Riga Technical University, $5^{\text {th }}$ Series Computer Science, Applied Computer Systems, Vol. 17, (RTU Publishing, Riga), pp. 72-82.

2. Apshvalka, D. and Grundspenkis, J., (2005), Personal knowledge management and intelligent agent perspective, in: Proceedings of the $14^{\text {th }}$ International Conference on Information Systems Development PreConference-ISD 2005. Karlstad, Sweden, 14-17 August, 2005, edited by A. G. Nilsson, et. at. (Karlstad University Studies, Karlstad, Sweden), pp. 219-230.

3. Ellis, C. and Wainer, J., (2002), Groupware and computer supported cooperative work, in: Multiagent Systems. A Modern Approach to Distributed Artificial Intelligence, G. Waiss, ed. (MIT Press, Massachusetts), pp. 425-458.

4. Grundspenkis, J., (2001), Concepts of organizations, intelligent agents, knowledge, learning and memories: towards an inter-disciplinary knowledge management, in: Applied Computational Intelligence to Engineering and Business, K. Wang, J. Grundspenkis, and A. Yeerofeev, eds. (Riga Technical University Publishing, Riga, Latvia), pp. 172-191.

5. Grundspenkis, J., (2003), Development of hybrid intelligent systems: integration of structural modelling, intelligent agents and knowledge management techniques, Scientific Proceedings of Riga Technical University, $5^{\text {th }}$ series Computer Science, Applied Computer Systems, Vol. 17, (RTU Publishing, Riga), pp. 7-30.

6. Grundspenkis, J. and Kirikova, M., (2005), Impact of the intelligent agent paradigm on knowledge management, in: Intelligent KnowledgeBased Systems, C. T. Leondes, ed., Vol. 1: Knowledge-Based Systems (Kluwer Academic Publishers, Boston, Dordrecht, London).

7. Knapik, M. and Johnson, J., (1998), Developing Intelligent Agents for Distributed Systems (McGraw Hill, New York).

8. KM Magazine. Personal Knowledge Management, Vol. 7, Issue 7; www.kmmagazine.com.

9. Russell, S. J. and Norvig, P., (2003), Artificial Intelligence. A Modern Approach, (Pearson Education, Upper Saddle River, New Jersey).

10. Tsui, E., (2002), Technologies for Personal and Peer-to-Peer (P2P) Knowledge Management, CSC Leading Edge Forum Technology Grant Report.

11. Web Intelligence, (2003), edited by N. Zhong, J. Liu, and Y. Y. Yao, (Springer-Verlag, Berlin, Heidelberg).

12. Woodridge M., (2002), An Introduction to Multiagent Systems (John Wiley \& Sons, Chichester, West Sussex, England). 